\title{
UMA ANÁLISE SOBRE RENORMALIZAÇÕES E VARIABILIDADES NA PRÁTICA DO TRABALHO OFFSHORE
}

\author{
AN ANALYSIS OF RENORMALIZATIONS AND VARIABILITY IN THE PRACTICE \\ OF OFFSHORE WORK
}

\section{UN ANÁLISIS DE RENORMALIZACIONES Y VARIABILIDAD EN LA PRÁCTICA DEL TRABAJO OFFSHORE}

\begin{abstract}
Rayana Ferreira Vinagre ${ }^{\mathrm{i}}$
Alexandre de Carvalho Castro ${ }^{\mathrm{ii}}$

Resumo: Este trabalho tem o objetivo de analisar a atividade de trabalho no regime offshore valendose de contribuições da ergologia. A metodologia utilizada para a realização desta pesquisa consistiu em três etapas: a primeira foi fazer um levantamento bibliográfico, que foi a base teórica para fundamentar a discussão; a segunda etapa foi a realização de entrevistas utilizando o método de instrução ao sósia; e a terceira etapa foi a análise da entrevista identificando aspectos da abordagem ergológica da atividade de trabalho. Concluiu-se que o trabalho offshore possui constantes necessidades de renormalizações e muitas variabilidades, interferindo nas práticas de atividade de trabalho.

Abstract: This work aims to analyze work activity in the offshore regime using contributions from ergology. The methodology used to carry out this research consisted of three stages: the first was to carry out a bibliographic survey, which was the theoretical basis to support the discussion; the second stage was the conduct of interviews using instruction to the double method; and the third step was the analysis of the interview identifying aspects of the ergological approach to work activity. It was concluded that offshore work has constant needs for renormalizations and many variability, interfering in work activity practices.

Resumen: Este trabajo tiene como objetivo analizar la actividad laboral en el régimen offshore utilizando contribuciones de la ergología. La metodología utilizada para llevar a cabo esta investigación consistió en tres etapas: la primera fue realizar una encuesta bibliográfica, que fue la base teórica para apoyar la discusión; la segunda etapa fue la realización de entrevistas utilizando el método de doble instrucción; y el tercer paso fue el análisis de la entrevista identificando aspectos del enfoque ergológico de la actividad laboral. Se concluyó que el trabajo en alta mar tiene constantes necesidades de renormalizaciones y mucha variabilidad, lo que interfiere en las prácticas de la actividad laboral.
\end{abstract}

Palavras-chave: Ergologia; Atividade de Trabalho; Offshore.

Keyword: Ergology; Work Activity; Offshore.

Palabra clave: Ergología; Actividad laboral; Offshore. 


\section{INTRODUÇÃO}

A atividade de trabalho offshore é caracterizada como aquela realizado em alto mar, em plataformas marítimas, em regime de embarque, na maioria das vezes. Os embarques são programados considerando a escala de trabalho e as necessidades da plataforma. Há vários tipos de escalas de trabalho, variáveis de acordo com a empresa e com o cargo do trabalhador, elas podem ser: 14 por 14, 14 por 21, 28 por 28 ou outras escalas, onde esses números significam dias de embarque e dias de folga, respectivamente.

A lei no 5.811/72 (BRASIL, 1972) dispõe sobre o regime de trabalho dos empregados nas atividades de exploração, perfuração, produção e refinação de petróleo, industrialização do xisto, indústria petroquímica e transporte de petróleo e seus derivados por meio de dutos. Segundo CASTRO (2013), por esse motivo, o trabalho em plataformas marítimas possui características bem específicas no que diz respeito à remuneração, aos períodos de trabalho e aos de descanso.

Alguns aspectos psicológicos do trabalho embarcado já foram identificados e analisados em estudos realizados por Castro e Vinagre (2009) e Vinagre et al (2014), sobre a percepção do tempo subjetivo e sobre turnos de trabalho e fatores humanos.

Há de se exaltar a necessidade de compreensão singular dessa forma de trabalhar, visto que, além das atribuições próprias das profissões, os trabalhadores também estão expostos a uma condição ambiental toda especial, em função de um espaço fisico "à parte" da sociedade - a plataforma ou o navio - e de uma situação de isolamento e confinamento - que afetam as relações de trabalho.

A ergologia, sendo mecanismo de estudo e análise da atividade de trabalho, oferece vários conceitos importantes e necessários para compreender a prática de profissionais offshore. Ao dar espaço de destaque para a percepção que o próprio trabalhador tem de sua atividade de trabalho, associada a aspectos organizacionais, a ergologia é uma importante forma de abordagem da atividade de trabalho porque permite considerar, entre outros, os aspectos psicofisiológicos e sociais que arraigam os trabalhadores e formam, no contexto de situação de trabalho, a prática da atividade propriamente dita.

Em 2013, Schwartz esclareceu, em entrevista concedida a Moacir Fernando Viegas, a ergologia da seguinte forma: "A ergologia, explicando de forma simples, é o estudo da atividade, porque a ergologia vem de um termo, de uma palavra grega (ergasesthai) que quer dizer “o fazer em geral”. A ergologia significa o estudo da atividade humana [...]. Há trinta anos, o ponto de partida do que hoje se chama ergologia era o interesse pelo trabalho (SCHWARTZ, 2013). 


\section{Metodologia}

A metodologia desta pesquisa consistiu em três etapas: a primeira foi a de fazer um levantamento bibliográfico sobre ergonomia, ergonomia da atividade e ergologia, buscando base para a discussão aqui proposta: analisar a atividade de trabalho do trabalhador offshore sob a perspectiva da ergologia.

A segunda etapa deste trabalho foi a realização de entrevistas com os trabalhadores offshore utilizando o método instrução ao sósia. Esse método incita o trabalhador a descrever a sua atividade de trabalho, dando instruções ao seu "sósia" para que este execute a sua atividade de forma que ninguém perceba a substituição do trabalhador. Oddone (1981) propôs o seguinte discurso para aplicação do método:

\footnotetext{
Se existisse uma outra pessoa perfeitamente idêntica a ti próprio do ponto de vista físico, como é que lhe dirias para se comportar na fábrica, em relação à sua tarefa, aos seus colegas de trabalho, à hierarquia, e à organização sindical (ou a outras organizações de trabalhadores) de forma a que ninguém se apercebesse que se tratava de outro que não tu? (ODDONE; RE;BRIANTE, 1981, apud TOGNATO, 2008)
}

A instrução ao sósia mostra-se um método bastante aderente para estudos que se valem da ergologia como forma de compreensão da atividade de trabalho, visto que valoriza a experiência do trabalhador em situação de trabalho.

As entrevistas foram realizadas pelas alunas Yasmin de Paula Alvarez e Isabella Assis de Figueiredo, do Curso Técnico em Segurança do Trabalho do CEFET/RJ, Campus Maria da Graça, como atividade aderente ao projeto de extensão "Estudo Introdutório da Ergonomia da Atividade - Uma abordagem Ergológica da Atividade de Trabalho”, realizado em 2018; e pela aluna de Iniciação Científica Larissa Brillo Nunes Rúbio, através da pesquisa "Saúde e Segurança no Trabalho Offshore", realizada nos anos de 2015 e 2016 com o apoio do programa CEFET/RJ-CNPq/PIBIC. Todas as entrevistas foram gravadas e transcritas para viabilizar a análise. As duas atividades foram coordenadas pela autora, que é docente da instituição.

A terceira etapa consistiu na análise da entrevista buscando identificar características de trabalho singulares, sob a interpretação e conceitos da ergologia.

\section{Discussão E RESUltados}

Um importante ponto identificado neste estudo a ser destaque na percepção da atividade de trabalho offshore é a "passagem de serviço" para o colega que vai dar continuidade ao trabalho na virada da equipe. Para alguns cargos, esta prática é uma norma prescrita, em documento próprio sobre a comunicação do trabalho, mas a forma de construção deste 
documento é bem particular, sem rigor técnico, como no caso de um dos profissionais entrevistados, que exerce o cargo de técnico em segurança do trabalho.

Esse processo, que é normativo, cria espaços para as renormalizações, visto que evoca a memória, a experiência e as prioridades do trabalhador que está deixando a plataforma/navio e passando a continuidade do trabalho para outro. O que será listado ou dissertado nessa passagem de serviço tem a ver, sobretudo, com a visão que o trabalhador teve de sua jornada a bordo, o andamento de cada serviço e as pendências, como podemos perceber no depoimento a seguir:

Nós temos um instrumento de passagem de serviço, você é minha back to
back, vou redigir um texto enorme, do tamanho que precisar ser, mesmo
se não acontecer nada de mais: “tá tudo ok, fulano de tal da base pediu pra
verificar isso, isso e isso ontem e não deu tempo. Comecei fazer essa
semana o DDS sobre joias, dá continuidade." Escrever tudo que
aconteceu e o que é de suma importância para você, como Técnica de
Segurança, saber o que eu passei durante esses 14 dias. (Embarcado 1)

A fala marcada sobre "o que é de suma importância para você" evidencia a prática individual do trabalhador em construir sua atividade de trabalho (neste caso, narrar o ocorrido no período do embarque), em função da sua experiência e de seus valores enquanto profissional. Ao mesmo tempo que é uma evocação oriunda de percepção particular, tal ação é afetada e afeta o coletivo de trabalho, pois está inserida em uma vivência coletiva, mas em tempos diferentes, o passado (o que foi feito) e o futuro (possíveis afazeres).

De fato, sabe-se que a atividade de trabalho em si, mesmo com todas as instruções e previsões possíveis, quando for realizada, ganhará forma própria, jamais idealizada integralmente pelo instrutor, mas totalmente emoldurada por quem a executa. Pois, segundo Teiger (1998), o trabalho é uma atividade finalizada, contextualizada e situada; não é neutra, pois compromete e transforma quem a realiza. O trabalho é uma atividade viva, que tem forma, movimento e objetivo, dados por quem o realiza.

Outro trabalhador entrevistado nessa pesquisa atua como oficial de náutica e possui diversas atividades distintas dentro da embarcação, tais como gerenciar a navegação do navio, zelar pela segurança da embarcação através de verificação de itens de prevenção e combate a incêndio, por exemplo.

O profissional entrevistado relatou que a maioria das normas de trabalho recebidas não são muito claras em questões operacionais, exigindo do trabalhador, a necessidade de torná-las executáveis. Essa condição solicita que o embarcado faça uso de seus conhecimentos técnicos, profissionais e utilize experiências passadas, como pode ser percebido na fala do embarcado 2, a seguir: 
Quando a gente tem que fazer os exercícios simulados a bordo, a gente (...), 'cê' tem, lógico, as recomendações que o comandante, o imediato, que a gente passou, a fim de presidir o exercício. Ele te diz, basicamente, o que você tem que fazer, mas você não necessariamente tem que seguir o padrão de exercício. Por exemplo, a gente vai fazer uma simulação de combate a incêndio e aí você tem diversas localidades, ele pode chegar pra você e falar: 'Olha só, quero que você simule (...), você faça uma simulação de exercícios', mas você pode fazer simulação em diversas parte do barco e cada uma tem sua peculiaridade, entende? E aí você (...), vai ficar a seu critério, fica mais subjetivo.[...] Você pode fazer de diversas formas diferentes... (Embarcado 2)

Nessa fala, percebe-se que as normas têm força hierárquica e há uma grande oportunidade para o trabalhador usar-se de si para poder cumprir a norma. Verifica-se também uma lacuna bastante explorável pelas renormalizações, já que estas se fazem necessárias frequentemente, para tornar exequíveis as atividades determinadas pelas normas.

Esta pesquisa identificou algumas variabilidades muito singulares das situações de trabalho analisadas, como, por exemplo, ser surpreendido com a presença indesejada de um clandestino na embarcação. Apesar dessa situação não ter nada a ver, diretamente, com o serviço do oficial de náutica, é uma ocorrência não tão rara assim, como pode-se perceber no depoimento a seguir:

[...] tem vários livros que a gente tem que registrar e tudo mais pra ver se não tem nenhum clandestino, principalmente em viagens internacionais, $\mathrm{o}$ pessoal costuma invadir muito barco pra poder viajar de um país pro outro. [...] Aí você tá fazendo a ronda no barco, aí deixa eu ver aqui o paiol de segurança..., aí 'cê' abre e tem um cara lá dentro. (Embarcado 2)

Percebe-se que o trabalhador offshore que é resultado de construções sociais tanto oriundos de sua vida pessoal, como também do meio de trabalho em que está inserido, necessita gerir sua prática de trabalho considerando todos os fatores daquele ambiente. A sua atividade de trabalho vai sendo moldada no momento em que emergem as circunstâncias, sendo elas imagináveis ou não. O trabalhador faz uso de si - por si, e por outros - para tomar decisões e construir sua prática laboral.

Outras variabilidades foram identificadas neste estudo, especialmente nos quesitos de segurança do trabalho, em situações de acidentes, conforme depoimento abaixo:

Já vi gente antiga no navio chorando por quase ter sofrido um acidente. Teve uma vez que o helicóptero caiu em cima de um navio nosso, foi um pouso forçado no navio. A empresa mandou trazer dois psicólogos depois 
disso, as pessoas estavam abaladíssimas. Não machucou ninguém, mas abalou todo mundo. (Embarcado 1)

Certamente, situações como essas modificam o ambiente de trabalho e interferem no clima e na cultura organizacional, e, consequentemente, transformam o trabalhador em um profissional mais experiente e mais rígido, talvez. Essa condição contribui para a formação do trabalhador, mesmo que ele não tenha sido influenciado fisicamente pelo acidente, ele foi influenciado psicologicamente.

$\mathrm{Na}$ sequência, o embarcado 1 relata mais um acidente de trabalho, que precisou da intervenção de profissionais competentes e experientes para livrar outros trabalhadores da morte:

[...] um cara que era mergulhador, e fizeram uma mistura de gás, porque você não respira só oxigênio. Nesse dia, eles erraram. Quando você entra no navio vai pra uma câmara de pressão, e vai pro sino, tudo pressurizado, esse sino desce todo dia pra fazer o trabalho. Mas ele fica a quinzena dele sob pressão. Eram quatro pessoas no sino. No dia parecia filme de terror, os quatro caíram, porque baixou o nível de oxigênio. É monitorado por câmeras, e quem monitora viu eles se debatendo no chão, e eles não podiam fazer nada, só descobrir o defeito e consertar. Ninguém morreu, eles consertaram lá. Mas o susto foi grande, muito grande. (Embarcado 1)

A fala "eles consertaram lá" indica expertise dos profissionais que estavam controlando o sino (ou câmara hiperbárica), que fizeram um uso de si racional e fundamental, acionando seus conhecimentos técnicos para solucionar o problema e salvar a vida dos colegas.

\section{CONCLUSÃO}

Assim, percebe-se que as atividades de trabalho offshore possuem características muito particulares, como as necessidades constantes de diversas possíveis construções de renormalizações, visto que as normas nem sempre são limitadas no passo-a-passo. Elas, as explícitas aqui neste estudo, permitem uma ação que evoca as habilidades profissionais dos trabalhadores, valendo-se dos usos de si - em função de valores pessoais e habilidade/formação profissional -, da cultura organizacional e dos coletivos de trabalho identificados nas práticas.

Outros aspectos que cabem ao trabalho offshore dizem respeito às variabilidades no ambiente de trabalho, que provocam no trabalhador a criatividade e incitam a expertise para lidar com tais situações, que foram exemplificadas neste estudo como a presença de um clandestino a bordo e a ocorrência de acidentes de trabalho. 


\section{REFERÊNCIAS}

BRASIL. Lei 5.811, de 11 de outubro de 1972. Dispõe sobre o regime de trabalho dos empregados nas atividades de exploração, perfuração, produção e refinação de petróleo, industrialização do xisto, indústria petroquímica e transporte de petróleo e seus derivados por meio de dutos. Diário Oficial da República Federativa do Brasil, Brasília, DF, out. 1972. Disponível em: <http://www.planalto.gov.br/ccivil_03/LEIS/1970-1979/L5811.htm>. Acesso em: 10 jul. 2019.

CASTRO, A.C. Produção Offshore na Bacia de Campos (RJ): a perspectiva da Psicologia do Trabalho. Gest. Prod., São Carlos , v. 20, n. 4, p. 833-846, 2013.

CASTRO, Alexandre de Carvalho.; VINAGRE, Rayana Ferreira. A percepção do tempo subjetivo e o estresse no trabalho offshore. In: XXIX ENCONTRO NACIONAL DE ENGENHARIA DE PRODUÇÃO. Salvador. Bahia: Anais do XXIX Encontro Nacional de Engenharia de Produção. 2009.

SCHWARTZ, Y. Histórico e conceitos da ergologia: entrevista com Yves Schwartz. Entrevista com Yves Schwartz, por Moacir Fernando Viegas. Reflexão \& Ação, v. 21, n. 1, p. 327-340. 2013.

TEIGER, C. El trabajo, ese oscuro objeto de la Ergonomía. In: Ergonomia: conceptos y métodos. Madrid. Espanha. Madri: Editorial Complutense, 1998. p. 141-162.

TOGNATO, M.I.R. A (re)construção do trabalho do professor de inglês pela linguagem. 2008. 337 p. Tese (Doutorado em Linguística Aplicada e Estudos da Linguagem) - Programa de Estudos Pós-Graduados em Linguística Aplicada e Estudos da Linguagem, Pontifícia Universidade Católica de São Paulo.

VINAGRE et al. Avaliação das relações estabelecidas entre os turnos de trabalho e os fatores humanos em profissionais da indústria naval. In: XXXIV ENCONTRO NACIONAL DE ENGENHARIA DE PRODUÇÃO. Curitiba. Paraná: Anais do XXXIV Encontro Nacional de Engenharia de Produção. 2014.

\footnotetext{
' Doutoranda do Programa de Pós-graduação em Engenharia de Produção e Sistemas do CEFET/RJ. Email:rayanavinagre@gmail.com

ii Docente do Programa de Pós-graduação em Engenharia de Produção e Sistemas do CEFET/RJ. Email: o.aken@uol.com.br
} 